\title{
PERTAINING TO PRESTRESS
}

\section{Chapter 27}

\section{PERTAINING TO PRESTRESS}

\author{
Fred E. Koebel \\ Structural Engineer, Southwest Research Institute \\ San Antonio, Texas
}

The purpose of this paper is to summarize in some detail the application of prestressed concrete to coastal structures, explain the basic theories of prestressed concrete, and give an explanation of an application of prestressed concrete recently designed and used by the author.

\section{APPLICATION TO COASTAL STRUCTURES}

Prestressed concrete can be easily adapted for use in coastal structures. One fine example that can be cited is the construction of offshore platforms used for drilling or stationary equipment. The platform itself could be constructed as a prestressed flat slab, stressed in two directions. The supporting piles could be constructed of precast, prestressed, concrete piles. At least one major pile company is now making hollow pile sections up to 36 inches in diameter which have proven to be very satisfactory. These piles are driven in the same manner as any other standard pile. Since the concrete section is always in compression, handling stresses are not critical. The concrete is never cracked, hence there is a very high resistance to salt water action. These piles also have the advantage of being fireproof, as well as having a low malntenance expense. A prestressed, precast, flat slab can then be constructed and placed on top of these piles. Thls slab will be much lighter in weight than an ordinary concrete slab and will also have the advantage of never cracking or spalling. Thus the salt water will not have any detrimental effects. This slab will also be highly resistant to fire, and maintenance costs would be low. The result of such construction will be a rigid, permanent structure, able to resist wind, impact, and waves, with a marked degree of success.

In the same vein of thought is the application of prestressed concrete to dock and wharve construction. Once again prestressed piles in conjunction wath prestressed beams and girders would provide an excellent structural material for dock construction.

Standard warehouses, with span lengths greater than heretofore thought possible with concrete, could also be constructed from prestressed concrete. Columns, beams, girders, and floor slabs could all be prestressed. In many cases in Europe, the prestressed design of many buildings was chosen in competition over the reinforced concrete, steel, and timber designs. Recent advances in the design of prestressed concrete now enables the design to include continuous and rigid frame structures.

Another use for prestressed concrete is the construction of tanks and pipes. Watertightness is always of prime concern and by using pre- 


\section{COASTAL ENGINEERING}

stressing is virtually assured. Prestressing is applied in two directions in a method developed by the Preload Corporation. Both vertical and circumferential prestress is applied. This places the wall in compression a sufficient amount to overcome the tensile stresses caused by the outward pressure of the water. These tanks could be used for storage very satisfactorily. The same system is beins used in the manufacture of concrete pipes. A 40 mile pressure pipe line, 30 inches in dianeter with a two inch shell, designed to withstand pressures up to $280 \mathrm{psi}$, is under construction in Canada at present.

Barges have been built using reinforced concrete. They were unsatisfactory in that they were entirely too rigid and failed in tension when heavily loaded; however with prestressed concrete it would be possible to introduce enough precompression to overcome this failing and the end result would be a strong, water-tight barge. This method of construction would also be applicable to many other types of floating works including docks, breakwaters, floating platforms, and many other harbor structures.

\section{ADVANTAGES OF PRESTRESSED CONCPETE FOR COKSTAL STRUCTURES}

There are many advantages to be gained in using prestressed concrete. The primary advantage is the great savings possible in the materials used in the construction. It can be estimated that a large quantity of steel will be saved along with a small amount of concrete. With present steel and wood shortages, there exists a need for a material which can replace these critical materials, but still be as good as the original material. Prestressed concrete has the full capability of fllling this need. Prestressing also prevents any cracking of the concrete, thus making a very waterproof structure. There is no fear of marine borers or sea water action on prestressed concrete members as there would be on wood and steel members. Thus no added treatment is necessary nor is continued maintenance a large item of expense. Most of the structural members lend themselves easily to precasting or factory manufacture thus allowing a standardization of section which will decrease the initial first cost of the member. Long spans, heretofore not possible in reinforced concrete construction may be built giving large unobstructed areas for warehouses. The material has excellent fatigue properties and withstands impact loading very well, making it an excellent material for dock and pier construction. All of these advantages and still many others are being utilized by engineers in Europe and the United States in a great variety of structures.

\section{FURDAINENTALS OF PFESTRESSED CONCRETE}

Concrete is inherently an excellent material in compression; however in tension it fails at a very small percentage of the load it can carry in compression. In flexural members, this inability to carry tensile forces is particularly detrimental. The steel placed on the tension side of the flexural member deforms a greater amount than the concrete, causing cracks which makes the tensile portion of the member 


\section{PERTAINING TO PRESTRESS}

useless. This in turn decreases the shear resistance of the material thus causing larye web sections to be introduced. This in turn adds to the dead weight of the member. In prestressed concrete these shortcomings are remedied to a large extent.

Prestressing is nothing more or less than introducing stresses and deflections opposite in sense to those introduced when the structure is loaded whth dead load and IIve load. These stresses are introduced into the nembers by tensioning high tensile strength ware which is placed as reinforcing within the concrete members. The tenszoning can be done in two ways, either by pretensioning or by posttensioning, the steel wire. Prestressed, posttensioned concrete indicates that the prestress has been introduced after the concrete is poured and set to a satisfactory strength. The ends of the member are used as reactions for a jack. In order to do this it is necessary to prevent bond from developing betreen the steel and concrete. Whis can be done in many ways including using an asphalt material, coring a hole with a rubber tube, or coverins the rod with a paper or plastic naterial. inen posttensioned is used, the load is usually transmatted to the concrete by means of an end bearing device. In some instances grout is also forced around the wires after stressing and the wires bonded into the concrete. Prestressed, pretensioned, concrete indzcates that the prestress has been introduced into the wire before the concrete is poured. When the concrete is set to strength the wire is released and the load is transmitt $\equiv d$ to the concrete by bond. There are many methods of prestressing, both pretensioning and posttensioning, used in Europe and the undlea states today, but the basic fundamentals are identıcal in each and every method.

As an example of prestressing theories, take a simply supported beam with a dead load of wt/t and a superimposed live load of Pf's. The bending moments at the critical sections can be evaluated and from these moments both the dead load and live load stresses can be evaluated. The primary purpose of prestressing is to introduce prestress of such magnitude so that the dead load and live load tensile stresses are just balanced bi the magnitude of precompression. As an example of this see Figure 2.

The stress diagrams in Figure 1 indicate when the beam is loaded with dead load and live load the bottom fibers are just at zero stress. This would indicate that the beam is now practicaliy straight or similar to Its condition before loading at all. 'inus in the prestressed beam, the entire section is in compression making the entire depth effective in developing the internal resisting moment. Thus the ratio of depth of beam to span length is greatly reduced.

Shear stress when accompanied by diagonal tension 15 of prime importance in concrete design. In ordinary reinforced concrete shear stress is used as a measure of diagonal tension. It is necessary in the beam above, to provide reinforcing for the diagonal tension developed at the point of maximum shear. This reinforcing is provided by means of stirrups at the supports. In prestressed concrete however the condition is not the same. Shear stress is no Ionger taken as a measure 


\section{COASTAL ENGINEERING}

of diagonal tension and the values of the diagonal tension are also reduced by the action of the prestress forces. This can be show quite effectively by the use of Mohr's circle of stress and the failure envelope that can be obtained for the concrete. A concrete cylinder indicated failure at 3000 psi when tested in compression. The same concrete failed in tension at a stress of 450 psi when subjected to a tensile loading condition. If the condition of stress is known on two mutually perpendicular planes, these conditions can be plotted on a circle of stress known as Mohr's. circle. From this circle of stress the condition of stress existing on any plane can readily be obtained. With the results of tests known and shown above, two circles of stress can be drawn. From these two circles of stress the envelope of rupture can be drawn. Any condition of stress that falls outside of this envelope indicates failure of the material. The value of "C" indicates the shear strength of the material without any normal stress. Two cases of loading of the concrete are shown. Case I is the conditzon of stress that exists when ordinary reinforced concrete is used. If the value of the cohesive stress is developed, the member will fail in tension and therefore the full cohesive strength of the material cannot be developed. Consequently, it is necessary to add reinforcing and increase the thickness of the section. In case II with a prestressing stress of .3 of the ultimate strength of the concrete, the full cohesive strength of the matarial can be fully developed without failure of the member. Thus it is possible to decrease the section, which will decrease the shear stress due to dead load. This characteristic of prestressed concrete overcomes to a large degree one of the basic shortcomings of reinforced concrete.

Hence by using prestressed concrete the section behaves almost as a steel beam in that the section can be developed to its full depth to resist mornent, the section remains in compression hence no tensile cracks are formed, and the resistance to shiar is greatly increased.

\section{PHESTTZESSED ROOF SIAB}

A prestressed slab, tensioned in two directions, was constructed at the Southwest Research Institute to determine the applicability of prestressing to flat slabs. The slab was posttensioned in two directrons mutually perpendicular to each other. The slab was 88 feet in length and 30 feet in width. The thickness of the slab was six inches. The slab was supported on eight columns with a maximum span between columns of 24 feet and a maximum cantilever of 10 feet. The steel was laid and the slab formed, poured, and stressed on the ground and then lifted into place following the usual practices of the Youtz-Slick Lift Slab Method of building construction. In the Youtz-Siick Method, all slabs are poured on the ground, one on top of the other, and then lifted into place by hydraulic jacks placed on top of the columns. The slabs are lifted by long screws extending from the jack into the slab and fastened therein to a lifting collar. The lifting collar serves a dual purpose, both as a means of lifting, and as a structural shear head to distribute the reaction of the column into the slab. When the slab is lifted into place the slab is fixed to the columns by welding. 
PERTAINING TO PRESTRESS

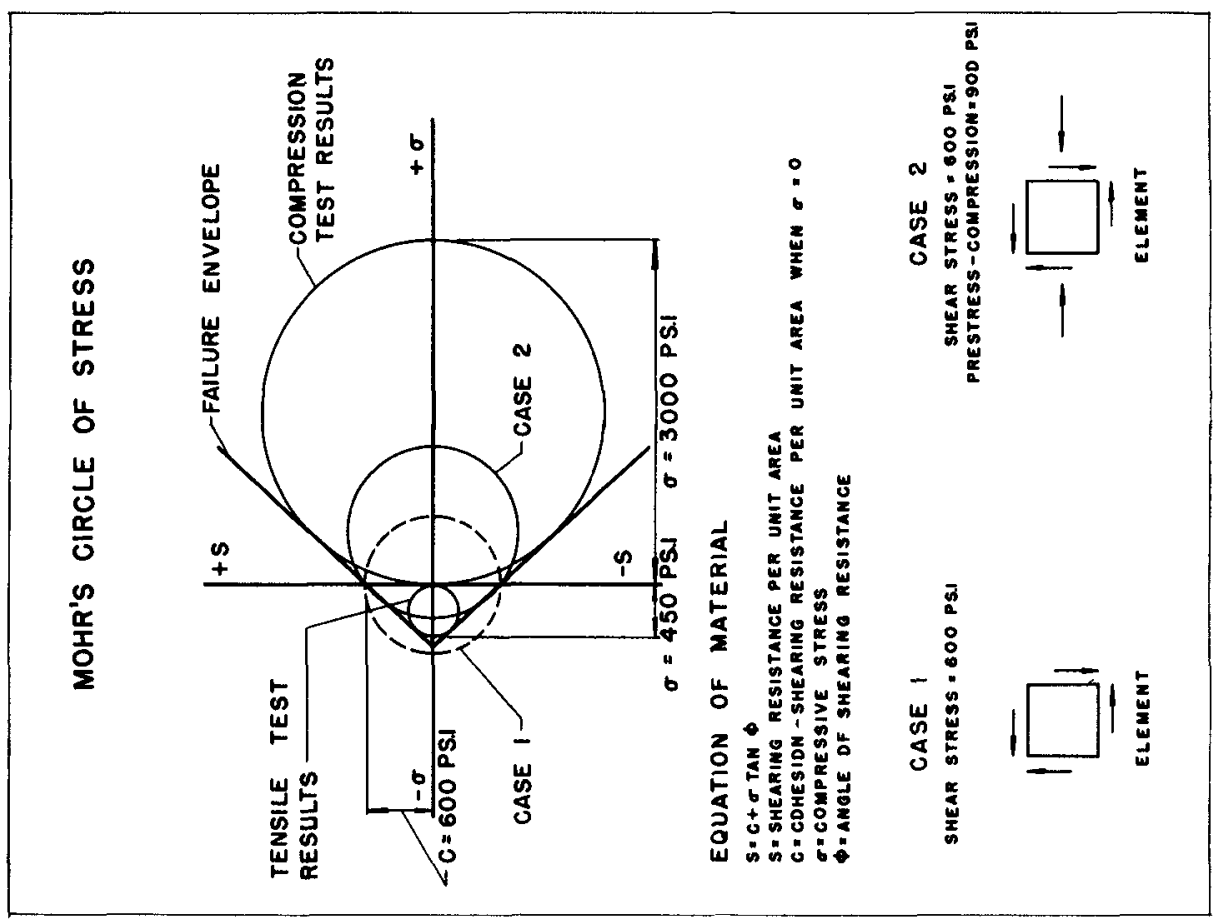

悉

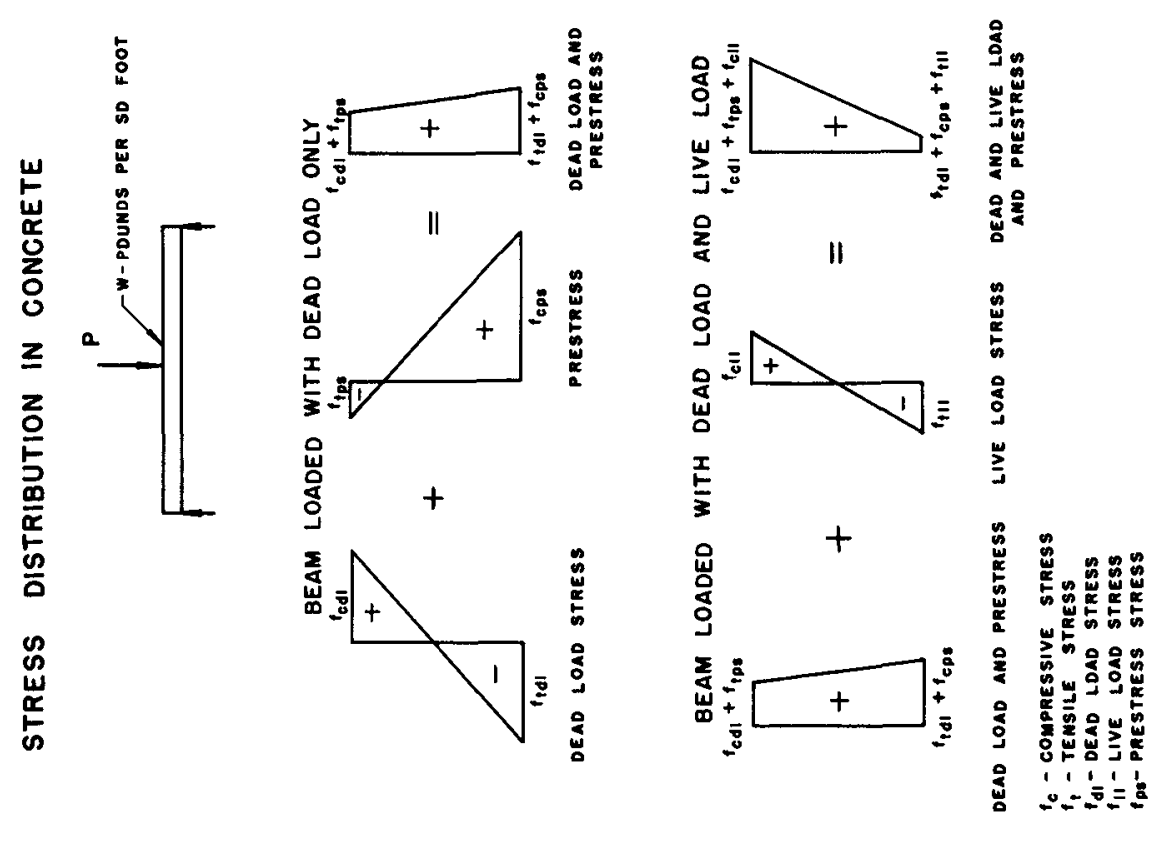




\section{COASTAL ENGINEERING}

A one-sixth model of the roof slab was built in order to ascertain the behavior of the slab. All linear dimensions of the slab and steel were reduced by a factor of six. SR-4 strain gages and Ames dial gages were mounted at critical sections to deternine stresses, deflections, and strains, in the slab when subjected to dead load and live load conditions.

\section{DESIGN CONSIDERATIONS}

The slab was analyzed and designed as a horiziontal gridwork of beams intersecting at right angles. Using this system the moments due to dead load and live load were determined and the section and quantity of steel necessary was obtained. The steel used was one-quarter of an inch in diameter, high tensile strength steel. The ends of the steel rods were upset and ihreaded through end bearing plates in groups of six and anchored at the ends of the slab. Since the steel was posttensioned, a heavy coat of asphalt was applied to the steel to prevent bond. Poststressing was done in two different ways. Along the long dimension of the slah, each group was puiled individually using a stressing plate which remained in the slab after stressing. When the wires were fully stressed shims were placed between the stressing plate and the end bearing plate to hold the desired increment of strain. Across the short dimension, stress was introduced into the wares by separating sections of the slab. The slab was poured in two sections, with only the wires continuous across the opening. Openings were left in the slab for hydraulic jacks and when the concrete was set to strength the two sections of the slab were jacked open a predetermined distance. The opening was then routed in with a fast setting, rout and the jacks removed when the grout reached desired strength. The attempt of the slab to pull back together thus introduced the prestress into the slab. A working stress of 110,000 ps 1 was developed in the steel and a stress of 1400 psi compression was developed in the concrete. When the structure is fully loaded with dead load and live lood, there is no bending tensile stress developed in the concrete.

The concrete mix was designed for a 28 day strength of 5000 psi. cylinder tests indicated that this strength was reached in about 10 days. The concrete had a cement content of 7 sacks per yard. The concrete was poured with a slump of 3 inches.

\section{MODEL TEST}

The model test was performed to determine the behavior of the large slab. Readings of strain, load, and deflections were taken on the model and converted to full scale using the following relationships: 


\section{PERTAINING TO PRESTRESS}

Item

Stresses (bending)
Ful1

$$
S=\frac{M C}{I}
$$

(shear)

$$
S_{S}=\frac{V Q}{I t}
$$

$$
=\frac{\frac{S}{E}}{K W L^{3}}
$$

Model

$\mathrm{S}=\frac{\mathrm{MC}}{\mathrm{I}_{\mathrm{T}}}$

$S_{S}=\frac{V_{Q}}{I t}$

$=\frac{S}{E}$

$\frac{K N L^{3}}{6 E I}$

These relationships Indicate that stresses and strains are identical in the model and full size slab whle the measured or evaluated deflections in the model are one-sixth of those obtalned in the full scale test. This can be proven if it $\mathrm{is}$ assumed that the properties of the materials used in the moael are identzcal with the properties of the materials used in the full sized slab. If a factor of 6 is used, the dimensional properties of section change in accordance with the power of the property. For example, the moment of inertia is reduced by a factor of (6) 4 since this property is (in)4 and all Innear dimensions are reduced by $a$ factor of (6). The Total load $\pi$ is reduced by a factor of $(6)^{2}$ because the cross sectional area is reduced by $(6)^{2}$. The unit load $w$, $f / \mathrm{ft}^{2}$ remains the same in the model and full slab however.

\section{PESULTS OF MONEL STUDY}

When loaded w.th a dead load and live load equal in magnitude to the design load of the full sized slab, the deflection readings indicated that the slab was substantially level. In other words the deflection due to the prestressing moments were just about balanced by the deflections due to live and dead load. From the study of the electric strain gage readings, it was determined that the concrete had not gone into tension in any of the measured portions of the slab.

Further loading indicated that deflections and stresses developed did not become abnormally large. The model is presently loaded with a uniformly distributed load of 212 H/ $/ 2$ or 2.25 times its designed load. There are no cracks or spalling and the deflections have remained in the same magnitude as before. The slab will be allowed to retain this load for a long period of tume to determune any plastic flow or creep characteristics.

Another problem of particular concern was the shear developed around the lifting collar. The diagonal tension that 15 developed is one of the more critical items in the design of the slabs used with the Youtz-Slick Method. Wath a slab prestressed in two directions, the stress condition becomes triaxial. An analysis of this condition indicated that the magnitude of tension developed is very small compared with a conventional slab of the same dimensions. This analysis is very well substantiated by the model test as the magnitude of shear at the lifting collar is high enough to fail the concrete by diagonal tension under ordinary conditions. 


\section{COASTAL ENGINEERING}

\section{GENERAL CONSIDERATIONS}

In the slab constructed only 40 per cent of the weight of steel used in a comparable slab was used. There was only two-thirds of the usual amount of concrete used. Thus this indicates a substantial savings in dead weight which in turn lessens the size and cost of the footings, columns, and collars used. By using prestressed concrete, it is unnecessary to provide any built-up roof for waterproofing. With the use of prestress it will be possible to greatly increase the span lengths, and thus provide more unobstructed area.

\section{CONCLUSION}

There are many more possible uses for prestressed concrete. The material is applicable to many structures in all types of construction. It remains to be seen how American ingeniuty will adapt prestressing into standard construction procedures. The initial efforts have been made and have met with success. There are many disadvantages still to be overcome, but with the basic conceptions thoroughly established prestressed concrete stands on the threshold of nationwide acceptance.

\section{REFERENCES}

Freyssinet, E. - Prestressed Concrete - Principles and Applications; Institution of Civil Engineers, London, England.

Lalande, M. - The Variety of Applications of Prestressed Concrete; Cement and Concrete Association, London, England.

Magnel, G. - Prestressed Concrete - Its Principles and Applications; Cement and Concrete Association, London, England.

Magnel, G. - Prestressed Concrete - Concrete Publications Limited, London, England.

Parrett, J. T. - First Prestressed Piles Carry Tank Platform; Engineering News Record, July 5, 1951. 